\section{Anthropometry of arm: nutritional risk indicator in amyotrophic lateral sclerosis}

\author{
Cristina Cleide dos Santos Salvioni, 1 \\ Patricia Stanich, ${ }^{1}$ Acary Souza Bulle \\ Oliveira, 1 Marco Orsini2,3 \\ 1Department of Neurology and \\ Neurosurgical, Research on \\ Neuromuscular Disease, Federal \\ University of Sao Paulo; ${ }^{2}$ Centro \\ Universitário Augusto Motta, \\ Bonsucesso, Rio de Janeiro; ${ }^{3}$ Centro \\ Universitario Severino Sombra, Facuty of \\ Medicine, Vassouras, Brazil
}

\section{Abstract}

The aim of the paper is to examine the correlation between clinical data, nutritional, respiratory and functional parameters in amyotrophic lateral sclerosis (ALS). This is a descriptive study of 111 ALS patients [91 spinal onset (GS) and 20 bulbar onset (GB)] carried on using nutritional and respiratory parameters and amyotrophic lateral sclerosis functional rating scale (ALSFRS). ALSFRS was analyzed in the main domains (D1, D2 and D3). Forced vital capacity and anthropometric measurements, there was significant association for GS and GB, and in GS there was positive correlation with midarm circumference (MAC) ( $\mathrm{r}=0.30 ; \mathrm{P}=0.020)$, midarm muscle circumference $(\mathrm{r}=0.29 ; \mathrm{P}=0.026)$, arm muscle area $(\mathrm{r}=0.28 ; \mathrm{P}=0.033)$ and protein-caloric malnutrition score $(\mathrm{r}=0.27 ; \mathrm{P}=0.039)$, while for $\mathrm{GB}$ only with body weight $(\mathrm{r}=0.64$; $\mathrm{P}=0.024)$. On correlation of nutritional parameters and ALSFRS for GS patients we observed that MAC and \%MAC presented positive association with both issues of D1 and D2. For GB, the total score in addition to correlate positively with anthropometric parameters related to lean body mass also presented negative association with a parameter associated with body fat. In summary, it is suggested that the application of anthropometry of arm could be useful in routine monitoring of ALS patients.

\section{Introduction}

Amyotrophic lateral sclerosis (ALS) is a neurodegenerative disorder by characterized by upper and lower limbs and bulbar and respiratory muscle, due to a loss of upper and lower motor neurons. 1,2

Nutritional parameters of ALS patients worsened during disease evolution, and worse nutritional status was associated with a higher mortality. ${ }^{3,4}$ From a nutritional perspective, the body weight loss associated with bulbar changes (dysphagia and respiratory difficulty) demonstrates the need for early nutritional care. ${ }^{5}$ Muscle atrophy may mask the increased metabolic demand, which is characteristic of progressive diseases. The increased basal energy consumption in patients with ALS occurs because the energy is used to maintain pulmonary ventilation.6,7 Similarly, studies have shown increased energy expenditure at rest in $10 \%$ of these patients when compared to the healthy population, which is characteristic of an increased metabolism. In more advanced or terminal stages, these values are even higher. 8,9

The causes of hypermetabolism in ALS are not well understood. To date, the accepted causes are related to the reduction in lean body mass. The initial hypothesis to explain this paradox would be the increased respiratory muscle activity to maintain adequate gas exchange. ${ }^{10}$ A possible mitochondrial involvement in the hypermetabolism in ALS has been the focus of recent studies. ${ }^{6,9}$

The changes in nutritional status during disease progression are well known. Studies have shown a decrease in body weight, fat and lean mass, even with an adequate intake of energy and protein. ${ }^{11,12}$ Anthropometric measurements and indices most used to nutritionally assess ALS are: weight, weight loss as a percentage of usual weight and body mass index (BMI), which do not show changes in body compartments. ${ }^{13}$ For the nutritional assessment, arm anthropometry is recommended, considering that when the disease evolves, ALS patients usually lose muscle mass, bone density and therefore body weight.1,12,13 Anthropometry has been a valuable tool for identifying malnutrition in ALS.12,14 It is likely that anthropometry may reflect both the nutritional status as the loss of motor neurons. Both situations are likely to be influenced and may contribute to disease progression. ${ }^{13}$ Kasarskis et al. 12 in a pioneering study in 1997 , by using anthropometry of the arm and correlating it with disease progression, found a correlation between the arm muscle area and lung function (forced vital capacity) demonstrating the importance of body composition analysis with the progression of ALS. In this wise, we aimed in this study to correlate clinical, nutritional and respiratory parameters with functional parameters to identify the factors which determine the disease severity.

\section{Materials and Methods}

Descriptive study, cross-sectional with data collection of 111 ALS patients, treated at the
Correspondence: Cristina Cleide dos Santos Salvioni; St. Estado de Israel 899; 04022-020 Sao Paulo, SP, Brazil.

E-mail: cris.salvioni@gmail.com

Key words: Nutritional assessment; anthropometry; amyotrophic lateral sclerosis; rehabilitation; motor neuron disease.

Contributions: CCSS and PS have made substantial contributions to conception and design; CCSS, PS, ASBO and MO have made substantial contributions to acquisition of data, or analysis and interpretation of data; CCSS and PS have been involved in drafting the manuscript or revising it critically for important intellectual content; all authors have given final approval of the version to be published.

Conflict of interest: the authors declare no potential conflict of interest.

Received for publication: 14 April 2015.

Revision received: 16 August 2015

Accepted for publication: 12 November 2015.

This work is licensed under a Creative Commons Attribution NonCommercial 3.0 License (CC BYNC 3.0).

(C) Copyright C.C. dos Santos Salvioni, et al., 2015 Licensee PAGEPress, Italy

Neurology International 2015; 7:5952

doi:10.4081/ni.2015.5952

Department of Neurology and Neurosurgery, Federal University of Sao Paulo (Brazil) between 2009 and 2010. All patients met the El Escorial diagnostic criteria for probable or definite ALS. ${ }^{15}$

Informed consent was obtained from all patients, and ethical approval was granted by the Ethical Research Committee of Federal University of Sao Paulo.

\section{Clinical characteristics}

The uptake of clinical data was performed in the medical records that included: site of onset (bulbar or spinal), referred time of disease (RTD) and date of diagnosis. For assessing the evolution time of disease, the following times were considered: $\mathrm{T} 1$, onset of symptoms until diagnosis confirmation; T2, between the onset of symptoms and the nutritional and T3 evaluation, between diagnostic confirmation and nutritional assessment. The schematic representation of the times evaluated can be found in Figure 1.

\section{Respiratory and nutritional assess- ment}

Forced vital capacity (FVC) expressed as percentage of the predicted value for age and sex, was recorded for all patients. The proce- 
dure was performed consecutively to nutritional assessment. The BMI was calculated and classified according to the age group for adults and seniors. 16,17

The arm measurements assessed were: triceps skinfold thickness (TSF) and midarm circumference (MAC), and then calculated the arm muscle area (AMA), midarm muscle circumference (MAMC) and arm fat area (AFA). The TSF, MAC, AMA, MAMC and AFA were evaluated using the methods proposed by Frisancho. ${ }^{18}$

For the classification of nutritional status, the BMI and the measurements of the arm were analyzed in an isolated way, and later in association with the protein-caloric malnutrition score (PCMS). 19 The PCMS is based on the percentage of the predicted value of all assessed values: \%TSF, \%MAC,\%AMA,\%MAMC and \%AFA. In other words, each parameter is compared to the reference population measurements and then all the results are added together and divided by the number of evaluated parameters. The PCMS considers the body compartments, muscle mass and fat, rather than total body mass, thus differentiating from the BMI.

\section{Amyotrophic lateral sclerosis func- tional rating scale}

The Amyotrophic Lateral Sclerosis Functional Rating Scale (ALSFRS) 20 was applied at the time of nutritional assessment. Each item was analyzed individually and grouped in the main areas. Domain 1 (D1) is associated with bulbar function and understands the issues $\mathrm{A}, \mathrm{B}$ and $\mathrm{C}$ with a minimum score of 0 and a maximum of 12 points. Domain 2 (D2) refers to motor aspects including upper and lower limbs and covers issues D, E, E1, F, G, H and I with a minimum score of 0 and a maximum of 24 points. Domain 3 (D3) is relevant to respiratory function and involves the question $\mathrm{J}$ with a minimum score of 0 and a maximum of 4 points.

Each item of the scale was correlated according to the site of onset (bulbar or spinal) with clinical characteristics and respiratory and nutritional assessment.

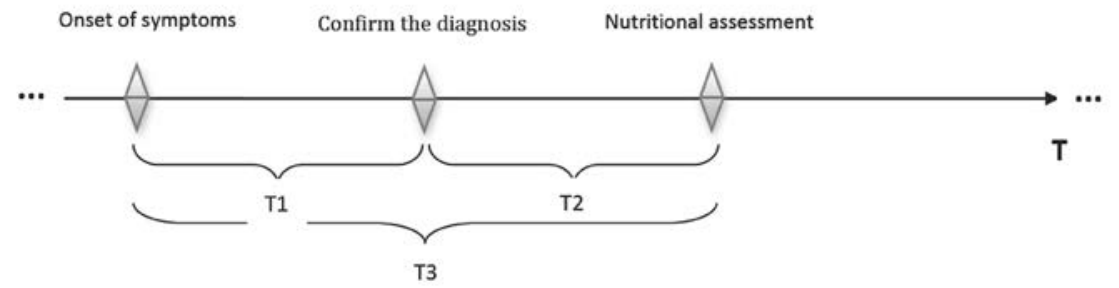

Figure 1. Schematic representation of the times evaluated. $T$, time; $T 1$, onset of symptoms to confirm the diagnosis; T2, time between onset of symptoms and nutritional assessment; T3, time between diagnostic confirmation and nutritional assessment. Bulbar Onset (GB). All but 23 of the patients were treated with $100 \mathrm{mg}$ of Riluzole per day; none took steroids. No patient reported receiving nutritional counseling from the beginning of disease symptoms.

For all studied moments we found more intervention precocity for GB, however we only obtained significant difference $(\mathrm{P}<0.012)$ when we analyzed the $\mathrm{T} 2$ which covers the period between

Correlating the time periods studied (T1, T2 and T3) with anthropometric parameters for the GS, we observed that the T2 showed a statistically significant positive correlation with \%TSF ( $\mathrm{r}=0.25 ; \mathrm{P}=0.025)$ and negative with measurements related to the estimate of muscle mass, MAMC ( $\mathrm{r}=-0.23 ; \mathrm{P}=0.034), \%$ MAMC $(\mathrm{r}=-0.27 ; \mathrm{P}=0.015)$, AMA $(\mathrm{r}=-0.25 ; \mathrm{P}=0.022)$ and \%AMA ( $\mathrm{r}=-0.25 ; \mathrm{P}=0.025)$. For $\mathrm{T} 3$, a significant positive association was found with the TSF $\quad(\mathrm{r}=0: 27 ; \quad \mathrm{P}=0.022), \quad \% \mathrm{TSF} \quad(\mathrm{r}=0.42$; $\mathrm{P}=0.000)$ and negative for the \%MAMC $(\mathrm{r}=$
$0.25 ; \mathrm{P}=0.038)$. The $\mathrm{T} 1$ showed no significant association with any anthropometric parameter. The other analyzed measurements (BMI, MAC, \%MAC, AFA and \%AFA) did not correlate with times evaluated. For GB, we did not find statistically relevant correlation between the times evaluated with anthropometric parameters.

In the analysis between FVC and anthropometric measurements, there was significant association for both GS and for GB, and in the appendicular there was a positive correlation with the MAC measurements ( $\mathrm{r}=0.30$; $\mathrm{P}=0.020)$, MAMC ( $\mathrm{r}=0.29 ; \mathrm{P}=0.026), \% \mathrm{MAMC}$ $(\mathrm{r}=0.28 ; \mathrm{P}=0.038), \mathrm{AMA}(\mathrm{r}=0.28 ; \mathrm{P}=0.033)$ and PCMS ( $\mathrm{r}=0.27 ; \mathrm{P}=0.039)$, while for the bulbar group, just with body weight $(\mathrm{r}=0.64$ $\mathrm{P}=0.024)$.

Table 2 shows that the nutritional evaluation of groups differs, especially among the measurements that assess fat mass and BMI.

Considering the classification of BMI we found malnutrition more present in GB (40\%) compared to GS (25.6\%), data that confirm the Table 3 with a worse nutritional status for GB.

The correlation coefficients of nutritional parameters for ALSFRS and GS patients are presented in Table 4. The MAC and \%MAC had

Table 1. Demographic and anthropometric characteristics of the amyotrophic lateral sclerosis patients.

\begin{tabular}{lc} 
No of participants & Median \\
Gender (m ale) & $59.0(53.1 \%)$ \\
\hline Age (years) & $57.0(49.7-64)$ \\
Bulbar onset & $20(18 \%)$ \\
\hline Spinal onset & $91(82 \%)$ \\
T1 (months) & $19.3(9.1-30,8)$ \\
\hline T2 (months) & $36.8(20.8-56.6)$ \\
T3 (months) & $11.7(5.9-25.9)$ \\
\hline FVC (\%) & $54.6(26.7-68.5)$ \\
MAC (cm) & $25.5(23.0-28.0)$ \\
\hline \%MAC & $79.8(73.9-89.1)$ \\
TSF (mm) & $15.0(10.0-20.7)$ \\
\hline \%TSF & $83.3(56.0-121.1)$ \\
MAMC (cm) & $19.9(18.2-22.3)$ \\
\hline \%MAMC & $80.4(69.5-91.4)$ \\
AMA (cm²) & $23.3(17.9-31.8)$ \\
\hline \%AMA & $56.9(37.9-79.2)$ \\
AFA (cm²) & $1274.0(907.2-1778.0)$ \\
\hline \%AFA & $55.4(40.2-79.9)$ \\
BMI (Kg/m²) & $21.7(19.7-25.2)$ \\
\hline PCMS & $77.9(68.4-89.4)$ \\
Total ALSFRS & $18(10.0-26.2)$ \\
\hline
\end{tabular}

T1,2,3, time 1,2,3; FVC, forced vital capacity; MAC, midarm circumference; TSF, triceps-skinfold thickness; MAMC, midarm muscle circumference; AMA, arm muscle area; AFA, arm fat área; BMI, body mass índex; PCMS, protein-caloric malnutrition score; ALSFRS, amyotrophic lateral sclerosis functional rating scale. 
a positive correlation with both $\mathrm{D} 1$ issues as well as D2. The only variable that showed a statistically significant correlation with the D3 was the \%MAC ( $\mathrm{r}=0.26 ; \mathrm{P}=0.025)$. For measures related to body fat, we realize that the TSF and \%TSF showed positive correlations with some parameters of D1 and negative with D2, with statistically significant differences. The AFA and \%AFA only showed expressive positive association with some of the D1 items. The anthropometric measurements related to the estimate of lean body mass (MAMC,\%MAMC, AMA and \%AMA) were the ones that showed more issues with significant positive correlation with D2. None of them showed a statistically convincing correlation with D1 and 3.The total score of the scale did not show correlation with significant differences only in anthropometric parameters related to body fat (TSF, TSF\%, AFA, AFA\%).

The correlation coefficients of the nutritional parameters and ALSFRS for GB patients are shown in Table 5. There was no correlation with statistically suggestive differences in body weight, BMI and TSF with any issue of scale. Unlike GS patients,

for the GB ones, the total score of the scale besides correlating positively with anthropo-
Table 2. Comparison of the evaluated times of patients with amyotrophic lateral sclerosis according to the predominance symptoms.

\begin{tabular}{lccc} 
Variables & Spinal group, median & Bulbar group, median & P \\
T1 & $19.3(9.1-32.4)$ & $14.2(8.1-25.7)$ & 0.431 \\
T2 & $43.8(22.6-57.7)$ & $24.9(14.4-36.1)$ & $0.012^{*}$ \\
\hline T3 & $12.1(6.1-33.1)$ & $9.5(3.9-17.2)$ & 0.137 \\
\hline
\end{tabular}

$\mathrm{T} 1,2,3$, Time $1,2,3$ (in months). *P<0.05;

Table 3. Anthropometric profile of patients with amyotrophic lateral sclerosis according to the predominance symptoms.

\begin{tabular}{lccc} 
& Spinal group, median & Bulbar group, median & P \\
MAC & $26.0(23.0-28.0)$ & $23.8(23.0-26.2)$ & 0.118 \\
\%MAC & $81.3(74.3-90.6)$ & $76.1(71.5-85.3)$ & 0.250 \\
\hline TSF & $15.0(10.0-22.5)$ & $14.0(9.0-18.0)$ & 0.138 \\
\%TSF & $91.5(68.5-126.3)$ & $59.6(46.6-78.7)$ & $0.001^{*}$ \\
\hline MAMC & $19.9(18.1-22.3)$ & $20.2(18.3-22.3)$ & 0.898 \\
\%MAMC & $80.1(68.6-89.7)$ & $84.3(72.6-97.9)$ & 0.225 \\
\hline AMA & $23.0(17.9-31.8)$ & $24.1(17.2-31.7)$ & 0.681 \\
\%AMA & $55.7(36.9-74.1)$ & $63.6(41.8-94.1)$ & 0.257 \\
\hline AFA & $1286.5(907.2-1793.0)$ & $1206.5(817.7-1397.0)$ & 0.203 \\
\%AFA & $59.8(43.4-74.3)$ & $39.9(32.1-56.9)$ & $0.002^{*}$ \\
\hline BMI & $22.2(22.1-25.4)$ & $19.2(18.3-23.3)$ & $0.005^{*}$ \\
PCMS & $78.8(68.8-90.6)$ & $70.1(63.2-82.2)$ & 0.074 \\
\hline
\end{tabular}

${ }^{*} \mathrm{P}<0.05$; MAC, midarm circumference; TSF, triceps-skinfold thickness; MAMC, midarm muscle circumference; AMA, arm muscle area; AFA, arm fat area; BMI, body mass índex; PCMS, protein-caloric malnutrition score.

Table 4. Correlation between nutritional parameters and Amyotrophic Lateral Sclerosis Functional Rating Scale for spinal group.

\begin{tabular}{|c|c|c|c|c|c|c|c|c|c|c|c|c|c|}
\hline & & & omains & & & & & omains & & & & omain: & Total \\
\hline & & A & B & C & D & E & E1 & F & G & H & I & J & \\
\hline Weight & $\begin{array}{l}r \\
P\end{array}$ & $\begin{array}{c}0.22 \\
0.047^{*}\end{array}$ & $\begin{array}{c}0.27 \\
0.016^{*}\end{array}$ & $\begin{array}{c}0.29 \\
0.009 *\end{array}$ & $\begin{array}{c}0.21 \\
0.063\end{array}$ & $\begin{array}{c}0.16 \\
0.180\end{array}$ & $\begin{array}{c}0.28 \\
0.413\end{array}$ & $\begin{array}{l}0.19 \\
0.097\end{array}$ & $\begin{array}{c}0.18 \\
0.101\end{array}$ & $\begin{array}{c}0.05 \\
0.653\end{array}$ & $\begin{array}{c}0.12 \\
0.307\end{array}$ & $\begin{array}{c}0.03 \\
0.787\end{array}$ & $\begin{array}{c}0.25 \\
0.026^{*}\end{array}$ \\
\hline BMI & $\begin{array}{l}r \\
P\end{array}$ & $\begin{array}{c}0.19 \\
0.104\end{array}$ & $\begin{array}{c}0.31 \\
0.006^{*}\end{array}$ & $\begin{array}{c}0.26 \\
0.022^{*}\end{array}$ & $\begin{array}{c}0.20 \\
0.073\end{array}$ & $\begin{array}{c}0.15 \\
0.221\end{array}$ & $\begin{array}{c}0.29 \\
0.423\end{array}$ & $\begin{array}{c}0.18 \\
0.115\end{array}$ & $\begin{array}{c}0.22 \\
0.057\end{array}$ & $\begin{array}{l}0.07 \\
0.550\end{array}$ & $\begin{array}{c}0.04 \\
0.739\end{array}$ & $\begin{array}{c}0.11 \\
0.351\end{array}$ & $\begin{array}{c}0.24 \\
0.031^{*}\end{array}$ \\
\hline AMA & $\begin{array}{l}\mathrm{r} \\
\mathrm{P}\end{array}$ & $\begin{array}{c}0.20 \\
0.080\end{array}$ & $\begin{array}{c}0.33 \\
0.003^{*}\end{array}$ & $\begin{array}{c}0.34 \\
0.002 *\end{array}$ & $\begin{array}{c}0.32 \\
0.004^{*}\end{array}$ & $\begin{array}{l}0.23 \\
0.055\end{array}$ & $\begin{array}{c}0.11 \\
0.739\end{array}$ & $\begin{array}{c}0.28 \\
0.012^{*}\end{array}$ & $\begin{array}{c}0.30 \\
0.007^{*}\end{array}$ & $\begin{array}{c}0.10 \\
0.389\end{array}$ & $\begin{array}{c}0.13 \\
0.260\end{array}$ & $\begin{array}{c}0.15 \\
0.182\end{array}$ & $\begin{array}{c}0.32 \\
0.004^{*}\end{array}$ \\
\hline \%AMA & $\begin{array}{l}\mathrm{r} \\
\mathrm{P}\end{array}$ & $\begin{array}{c}0.10 \\
0.399\end{array}$ & $\begin{array}{c}0.30 \\
0.009^{*}\end{array}$ & $\begin{array}{c}0.37 \\
0.001^{*}\end{array}$ & $\begin{array}{c}0.26 \\
0.022^{*}\end{array}$ & $\begin{array}{l}0.16 \\
0.208\end{array}$ & $\begin{array}{l}0.31 \\
0.355\end{array}$ & $\begin{array}{c}0.22 \\
0.053\end{array}$ & $\begin{array}{c}0.29 \\
0.012^{*}\end{array}$ & $\begin{array}{l}0.08 \\
0.483\end{array}$ & $\begin{array}{c}0.04 \\
0.755\end{array}$ & $\begin{array}{c}0.26 \\
0.025^{*}\end{array}$ & $\begin{array}{c}0.29 \\
0.012^{*}\end{array}$ \\
\hline TSF & $\begin{array}{l}\mathrm{r} \\
\mathrm{P}\end{array}$ & $\begin{array}{l}-0.04 \\
0.755\end{array}$ & $\begin{array}{c}0.13 \\
0.245\end{array}$ & $\begin{array}{c}0.23 \\
0.042^{*}\end{array}$ & $\begin{array}{c}-0.24 \\
0.033^{*}\end{array}$ & $\begin{array}{c}-0.24 \\
0.047^{*}\end{array}$ & $\begin{array}{l}-0.07 \\
0.833\end{array}$ & $\begin{array}{l}-0.21 \\
0.063\end{array}$ & $\begin{array}{l}-0.19 \\
0.099\end{array}$ & $\begin{array}{c}-0.30 \\
0.006^{*}\end{array}$ & $\begin{array}{c}-0.29 \\
0.008^{*}\end{array}$ & $\begin{array}{l}-0.02 \\
0.891\end{array}$ & $\begin{array}{l}-0.15 \\
0.178\end{array}$ \\
\hline \%TSF & $\begin{array}{l}\mathrm{r} \\
\mathrm{P}\end{array}$ & $\begin{array}{c}0.12 \\
0.309\end{array}$ & $\begin{array}{c}0.23 \\
0.044^{*}\end{array}$ & $\begin{array}{c}0.27 \\
0.018^{*}\end{array}$ & $\begin{array}{l}-0.19 \\
0.103\end{array}$ & $\begin{array}{c}-0.29 \\
0.020^{*}\end{array}$ & $\begin{array}{c}0.50 \\
0.116\end{array}$ & $\begin{array}{l}-0.10 \\
0.370\end{array}$ & $\begin{array}{l}-0.10 \\
0.398\end{array}$ & $\begin{array}{l}-0.17 \\
0.138\end{array}$ & $\begin{array}{l}-0.09 \\
0.459\end{array}$ & $\begin{array}{c}0.03 \\
0.767\end{array}$ & $\begin{array}{l}-0.01 \\
0.938\end{array}$ \\
\hline MAMC & $\begin{array}{l}\mathrm{r} \\
\mathrm{P}\end{array}$ & $\begin{array}{c}0.18 \\
0.104\end{array}$ & $\begin{array}{c}0.22 \\
0.051\end{array}$ & $\begin{array}{c}0.17 \\
0.140\end{array}$ & $\begin{array}{c}0.50 \\
0.0001^{*}\end{array}$ & $\begin{array}{c}0.39 \\
0.001^{*}\end{array}$ & $\begin{array}{c}0.51 \\
0.094\end{array}$ & $\begin{array}{c}0.50 \\
0.0001^{*}\end{array}$ & $\begin{array}{c}0.49 \\
0.0001^{*}\end{array}$ & $\begin{array}{c}0.30 \\
0.006^{*}\end{array}$ & $\begin{array}{c}0.36 \\
0.001^{*}\end{array}$ & $\begin{array}{c}0.17 \\
0.131\end{array}$ & $\begin{array}{c}0.44 \\
0.0001 *\end{array}$ \\
\hline \%MAMC & $\begin{array}{l}r \\
P\end{array}$ & $\begin{array}{c}0.00 \\
0.989\end{array}$ & $\begin{array}{c}0.11 \\
0.342\end{array}$ & $\begin{array}{c}0.11 \\
0.344\end{array}$ & $\begin{array}{c}0.35 \\
0.002^{*}\end{array}$ & $\begin{array}{c}0.30 \\
0.014^{*}\end{array}$ & $\begin{array}{c}0.26 \\
0.439\end{array}$ & $\begin{array}{c}0.29 \\
0.011^{*}\end{array}$ & $\begin{array}{c}0.33 \\
0.004^{*}\end{array}$ & $\begin{array}{c}0.13 \\
0.256\end{array}$ & $\begin{array}{c}0.07 \\
0.527\end{array}$ & $\begin{array}{c}0.14 \\
0.241\end{array}$ & $\begin{array}{c}0.25 \\
0.029 *\end{array}$ \\
\hline AMA & $\begin{array}{l}\mathrm{r} \\
\mathrm{P}\end{array}$ & $\begin{array}{c}0.16 \\
0.151\end{array}$ & $\begin{array}{c}0.21 \\
0.062\end{array}$ & $\begin{array}{c}0.17 \\
0.126\end{array}$ & $\begin{array}{c}0.51 \\
0.0001 *\end{array}$ & $\begin{array}{c}0.41 \\
0.001^{*}\end{array}$ & $\begin{array}{c}0.37 \\
0.232\end{array}$ & $\begin{array}{c}0.48 \\
0.0001^{*}\end{array}$ & $\begin{array}{c}0.48 \\
0.0001^{*}\end{array}$ & $\begin{array}{c}0.281 \\
0.011^{*}\end{array}$ & $\begin{array}{c}0.32 \\
0.004^{*}\end{array}$ & $\begin{array}{l}0.18 \\
0.101\end{array}$ & $\begin{array}{c}0.43 \\
0.0001 *\end{array}$ \\
\hline \%AMA & $\begin{array}{l}r \\
P\end{array}$ & $\begin{array}{c}0.03 \\
0.776\end{array}$ & $\begin{array}{c}0.12 \\
0.292\end{array}$ & $\begin{array}{c}0.13 \\
0.254\end{array}$ & $\begin{array}{c}0.39 \\
0.001^{*}\end{array}$ & $\begin{array}{c}0.36 \\
0.003^{*}\end{array}$ & $\begin{array}{l}0.01 \\
0.989\end{array}$ & $\begin{array}{c}0.32 \\
0.004^{*}\end{array}$ & $\begin{array}{c}0.36 \\
0.001^{*}\end{array}$ & $\begin{array}{c}0.16 \\
0.179\end{array}$ & $\begin{array}{c}0.10 \\
0.391\end{array}$ & $\begin{array}{l}0.16 \\
0.159\end{array}$ & $\begin{array}{c}0.28 \\
0.015^{*}\end{array}$ \\
\hline AFA & $\begin{array}{l}\mathrm{r} \\
\mathrm{P}\end{array}$ & $\begin{array}{c}0.06 \\
0.592\end{array}$ & $\begin{array}{c}0.24 \\
0.040^{*}\end{array}$ & $\begin{array}{c}0.35 \\
0.002 *\end{array}$ & $\begin{array}{l}-0.06 \\
0.605\end{array}$ & $\begin{array}{l}-0.10 \\
0.448\end{array}$ & $\begin{array}{c}0.05 \\
0.877\end{array}$ & $\begin{array}{l}-0.06 \\
0.621\end{array}$ & $\begin{array}{l}-0.02 \\
0.876\end{array}$ & $\begin{array}{l}-0.17 \\
0.143\end{array}$ & $\begin{array}{l}-0.16 \\
0.153\end{array}$ & $\begin{array}{c}0.07 \\
0.572\end{array}$ & $\begin{array}{c}0.03 \\
0.830\end{array}$ \\
\hline \%AFA & $\begin{array}{l}r \\
P\end{array}$ & $\begin{array}{c}0.18 \\
0.113\end{array}$ & $\begin{array}{c}0.34 \\
0.002 *\end{array}$ & $\begin{array}{c}0.33 \\
0.003^{*}\end{array}$ & $\begin{array}{c}0.00 \\
0.999\end{array}$ & $\begin{array}{l}-0.06 \\
0.627\end{array}$ & $\begin{array}{c}0.21 \\
0.531\end{array}$ & $\begin{array}{c}0.09 \\
0.453\end{array}$ & $\begin{array}{c}0.10 \\
0.383\end{array}$ & $\begin{array}{l}-0.06 \\
0.583\end{array}$ & $\begin{array}{c}0.03 \\
0.829\end{array}$ & $\begin{array}{c}0.06 \\
0.634\end{array}$ & $\begin{array}{c}0.15 \\
0.192\end{array}$ \\
\hline PCMS & $\begin{array}{l}\mathrm{r} \\
\mathrm{P}\end{array}$ & $\begin{array}{c}0.20 \\
0.090\end{array}$ & $\begin{array}{c}0.41 \\
0.0001 *\end{array}$ & $\begin{array}{c}0.43 \\
0.0001 *\end{array}$ & $\begin{array}{c}0.18 \\
0.121\end{array}$ & $\begin{array}{c}0.07 \\
0.562\end{array}$ & $\begin{array}{c}0.54 \\
0.086\end{array}$ & $\begin{array}{c}0.19 \\
0.105\end{array}$ & $\begin{array}{c}0.23 \\
0.046^{*}\end{array}$ & $\begin{array}{c}0.02 \\
0.875\end{array}$ & $\begin{array}{c}0.08 \\
0.479\end{array}$ & $\begin{array}{c}0.18 \\
0.127\end{array}$ & $\begin{array}{c}0.28 \\
0.014^{*}\end{array}$ \\
\hline
\end{tabular}

${ }^{*} \mathrm{P}<0.05$; ALSFRS: A, Speech; B, . Salivation; C, Swallowing; D, Handwriting; E, Cutting food and handling utensils; El, Cutting food and handling utensils; F, Dressing and hygiene; G, Turning in bed and adjusting bed clothes; H, Walking; I, Climbing stairs; J,Rrespiratory function; BMI, Body mass index; MAC, midarm circumference; TSF, triceps-skinfold thickness; MAMC, midarm muscle circumference; AMA, arm muscle area; AFA, arm fat área; BMI, body mass índex; PCMS, protein-caloric malnutrition score. 
metric parameters, related to the lean mass estimate (MAMC, AMA and \%AMA) also showed expressive negative association with a parameter associated with body fat, \%TSF.

\section{Discussion}

The population studied represents the epidemiological characteristics of ALS described in the literature, such as the prevalence of appendicular involvement of bulbar.2,21

According to the studied moments, we obtained higher early diagnosis and referral to the nutrition service for GB. Our findings are supported by the literature regarding the differences in gravity, respiratory impairment, oropharyngeal dysphagia and accelerated weight loss in this group of patients. $10,22,23$

The clinical evolution of GB would be the determining factor to anticipate the diagnosis and referral to nutrition service, once notably malnutrition appears earlier in predominantly bulbar patients than in predominantly appendicular patients. ${ }^{23}$

Resuming the assessment related to the studied moments, and at this time, correlating them with the nutritional aspects, some meas- ures of the arm, particularly for GS, drew the attention. The positive correlation found between T2 (referred time of the disease until the date of nutritional assessment) and the \%TSF, and negative with all the muscle mass estimate measures, make it seem reasonable to accept that the delay in nutritional intervention negatively influences the loss of muscle mass. For T3 the correlation was limited to be positive for the TSF and \%TSF and negative for \%MAMC. The T3 mentions the delay in the elapsed time between the professional who performs the diagnosis and the referral to the nutrition service. The time between the symptomatic manifestation, diagnosis and evaluation allows inferences about the natural course of the disease without nutritional intervention. For patients with GB, we did not find statistically significant correlation between the times evaluated with anthropometric parameters. It is important to consider that the occurrence may be associated with a possible bias in the sample, as the relatively small number of patients in GB compared to GS. Desport et al., 10 showed that malnutrition was an independent prognostic factor for survival. In that study, the average between the initial symptoms and nutritional intervention ( $29 \pm 25$ months) was lower than in this study (43 months for the GS group). In a recent study, Marin et al. ${ }^{3}$ indicates that the deterioration of nutritional status should be more appreciated, once the correction of weight loss, from the diagnosis and during the course of the disease, can be as positive in patients survival as the use of Riluzole. The prognostic value of nutritional status enables to propose close monitoring after the diagnosis of ALS.

In addition to nutritional aspects, the respiratory parameters were also observed in the analysis of the $\mathrm{FVC} \%$ and anthropometric measurements. There was significant association for both GS patients as for GB ones. Cooperating with the results presented, Kasarskis et al.12 also found a correlation between the AMA and the FVC as percentage of predicted. The authors explain that the fact may be associated with the dynamics of lung function, so that for performing the tests, it is necessary the use of the diaphragm (innervated by $\mathrm{C} 3, \mathrm{C} 4, \mathrm{C} 5$ roots), intercostal muscles as well as the accessory muscles, especially the scalene (C4, C5, C6, C7) and sternocleidomastoid ones. It would not be surprising thus, that AMA, which estimates the cross-sectional area of biceps (C5, C6) and triceps (C6, C7, C8) would correlate with the dynamics of pulmonary function tests in these patients, as the

Table 5. Correlation between nutritional parameters and Amyotrophic Lateral Sclerosis Functional Rating Scale for bulbar group.

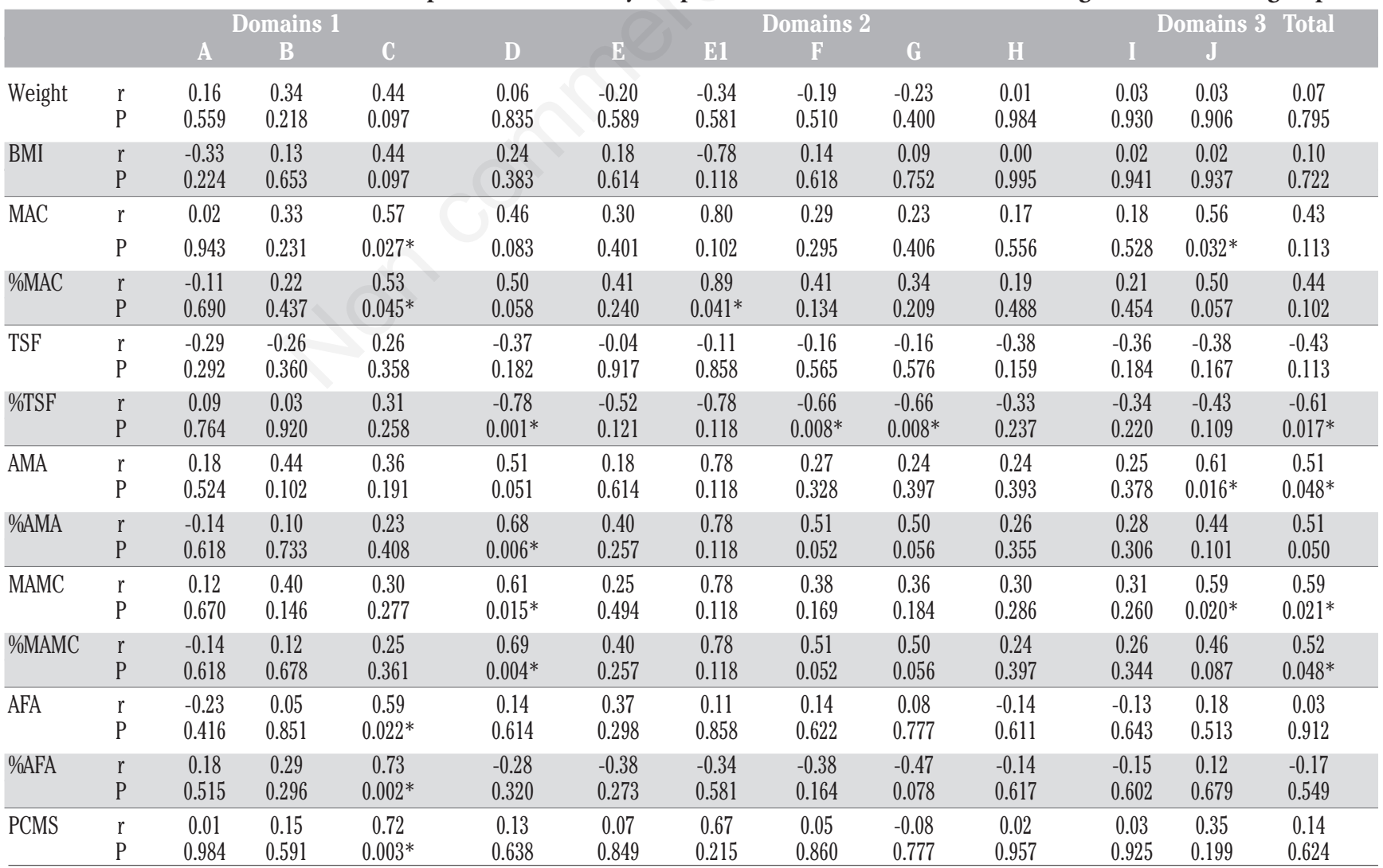

${ }^{*} \mathrm{P}<0.05$; ALSFRS: A, Speech; B, Salivation; C, Swallowing; D, Handwriting; E, Cutting food and handling utensils; E1, Cutting food and handling utensils; F, Dressing and hygiene ; G, Turning in bed and adjusting bed clothes; H, Walking; I, Climbing stairs; J, Respiratory function; BMI, Body mass index; MAC, midarm circumference; TSF, triceps-skinfold thickness; MAMC, midarm muscle circumference; AMA, arm muscle area; AFA, arm fat área; BMI, body mass índex; PCMS, protein-caloric malnutrition score 
motor neurons are affected. It seems reasonable to accept that the same happens with the MAC and MAMC, as both are estimated in the same location as the AMA. Such results suggest that the loss of respiratory quality may be a sign of nutritional decline and the opposite may also be true in patients with ALS.

In the anthropometric analysis, measures related to body fat showed significant differences between GS and GB patients, with lower values of median and percentiles for $\mathrm{GB}$ patients. Unlike the results presented herein, other studies found no significant differences when analyzing the arm anthropometry according to the pattern of disease onset.12,24 The classification of nutritional status by BMI also confirms the results obtained by the arm measures and PCMS, having the diagnosis of malnutrition present in $45.0 \%$ of patients with bulbar onset and $25.6 \%$ in GS, determining a difference of $19.4 \%$ amongst groups. The findings in this study were in accordance with the differences in nutritional behavior considering how the disease manifests itself, allowing us to characterize worse nutritional status in patients with bulbar onset commitment. ${ }^{23,25}$

By evaluating each item of ALSFRS for GS patients, the results suggest that when assessing arm anthropometry, in particular measurements that estimate muscle mass, it is possible to mention motor impairment as a result of disease progression. On the other hand, when applying the scale, especially in the D2 analysis, the evaluator of this domain may refer to the muscle mass compartment and therefore, have a good indication of the nutritional status for this group of patients. Skinfold measurements and calculation of muscle circumference provide information respectively from fat mass and fat-free mass. ${ }^{26}$ In ALS patients, AMA also monitors the progression of muscle atrophy, so perhaps, measurements of estimated lean mass showed good correlations with motor function. ${ }^{12}$ It is important to mention that the TSF, estimating measurement of body fat, showed a negative correlation with the items related to impairment of upper and lower limbs indicating negative influence to the motor aspect. It is worth mentioning that the body fat is already considered an important indicator of survival in MND/ALS and that even with the findings of motor worsening, restrictive diets should not be recommended. ${ }^{3,12,27}$ Contributing to the studies mentioned, the negative correlation between the estimate measures of body fat was limited to be negative only with D2. As for clinical aspects (D1) we found only positive correlations.

Still for GS patients, the total score of the scale showed close agreement with the nutritional aspects. Higher scores suggest better nutritional condition. The ALSFRS is already recognized by the association with objective measurements of muscle strength and lung function, however, there are no studies evaluating each item of the scale with nutritional parameters. ${ }^{20,28}$

For GB patients, no correlation with statistically significant differences between body weight and BMI with no question of scale nor with total score was observed. The isolated body weight and the BMI may not be the best indicators of nutritional decline for this population.13 The total score of functional scale showed a negative correlation with TSF\%, revealing that the positive influence of body fat would be limited only to bulbar aspects contained in D1. The same was not observed with GS patients, where the total score of scale did not correlate with the measures related to body fat. The numerical results presented should be interpreted carefully, since the TSF\% compares ALS subjects to a reference standard. 18 The measurements of body compartments when compared over the time would be the best choice so as to avoid a possible bias of the interpretation of results.

\section{Conclusions}

In short, the arm anthropometry proved to be as important as the isolated analysis from BMI and PCMS, substantiating the importance of its use for the nutritional assessment and disease progression. The ALSFRS, especially D2, indicated nutritional deficits. So that the application of the scale could serve as a screening tool in order to anticipate the referral to a nutritionist working with better prognosis in ALS.

\section{References}

1. Wijesekera LC, Leigh PN. Amyotrophic lateral sclerosis. Orphanet $\mathrm{J}$ Rare Dis 2009; $4: 3$

2. Oliveira ASB, Pereira RDB. Amytrophic lateral sclerosis (ALS). Three letters that change the people's life forever. Arq Neuropsiquiatr 2009;67:750-82.

3. Marin B, Desport JC, Kajeu P, et al. Alteration of nutritional status at diagnosis is a prognostic factor for survival of amyotrophic lateral sclerosis patients. J Neurol Neurosurg Psychiatry 2011;82:62834.

4. Shimizu T, Nagaoka U, Nakayama Y, et al. Reduction rate of body mass index predicts prognosis for survival in amyotrophic lateral sclerosis: a multicenter study in Japan. Amyotroph Lateral Scler 2012;13:363-6.

5. Miller RG, Jackson CE, Kasarskis EJ, et al.
The ALS practice parameter task force and the quality standards subcommittee of the American Academy of Neurology: Amyotrophic Lateral Sclerosis. Neurology 2010;11:7-60.

6. Desport JC, Preux PM, Magy L, et al. Factors correlated with hypermetabolism in patients with amyotrophic lateral sclerosis. Am J Clin Nutr 2001;74:328-34.

7. Pritchard J, Swingler RJ. Motor neuron disease: a review. Scott Med J 2000;45:4-7.

8. Desport JC, Torny F, Lacoste M, et al. Hypermetabolism in ALS: correlation with clinical and paraclinical parameters. Neurodegener Dis 2005;2:202-7.

9. Genton L, Viatte V, Janssens JP, et al. Nutritional state, energy intakes and energy expenditure of amyotrophic lateral sclerosis (ALS) patients. J Clin Nutr 2011;30:553-9.

10. Desport JC, Preux PM, Truong CT, et al. Nutritional assessment and survival in ALS patients. Amyotroph Lateral Scler Other Motor Neuron Disord 2000;1:91-6.

11. Nau KL, Bromberg MB, Forshew DA, Katch VL. Individuals with amyotrophic lateral sclerosis are in caloric balance despite losses in mass. J Neurol Sci 1995;129:47-9.

12. Kasarskis EJ, Berryman S, English T, et al. The use of upper extremity anthropometrics in the clinical assessment of patients with amyotrophic lateral sclerosis. Muscle Nerve 1997;20:330-5.

13. Worwood AM, Leigh PN. Indicators and prevalence of malnutrition in motor neuron disease. Eur Neurol 1998;40:159-63.

14. Silva LBC. Anthropometric wrist and arm circumference and their derivations: application to amyotrophic lateral sclerosis. Handbook of Anthropometry. New York: Springer Publication; 2012. pp 71726.

15. World Federation of Neurology research group on motor neuron diseases. El Escorial Revisited: Revised Criteria for the diagnosis of ALS. A consensus conference held at Airlie House, WORRENTON, 1998, Virginia, April 2- 4.

16. White JV, Dwyer JT, Possner BM, et al. Nutrition screening initiative: development and implementation of the public awareness checklist and screening tools. J Am Diet Assoc 1992;92:163-7.

17. World Health Organization. Physical status: the use and interpretation of anthropometry. Technical Report Series $n^{0} 854$. Geneve; 1995.

18. Frisancho A. Anthropometric standards for the assessment of growth and nutritional status. Ann Harbor: The University of Michigan Press; 1990.

19. Blackburn GL, Thorrnton PA. Nutritional assessment of the hospitalized patient. Med Clin N Am 1979;63:1103-15. 
20. Cedarbaum JM, Stambler N. Performance of the Amyotrophic Lateral Sclerosis Functional Rating Scale (ALSFRS) in multicenter clinical trials. J Neurol Sci 1997;152:S1-9.

21. Lee JR, Annegers JF, Appel SH. Prognosis of amyotrophic lateral sclerosis and the effect of referral selection. J Neurol Sci 1995;132:207-15.

22. Leigh PN, Ray-Chaudhuri K. Motor neuron disease. J Neurol Neurosurg Psychiatry 1994;57:886-96.

23. Mazzini L, Corrá T, Zaccala M, et al.
Percutaneous endoscopic gastrostomy and enteral nutrition in amyotrophic lateral sclerosis. J Neurol 1995;242:695-8.

24. Silva LB, Mourão LF, Silva AA, et al. Amyotrophic lateral sclerosis. Combined nutritional, respiratory and functional assessment. Arq Neuropsiquiatr 2008;66:354-9.

25. Ngo ST, Steyn FJ, McCombe PA. Body mass index and dietary intervention: Implications for prognosis of amyotrophic lateral sclerosis. J Neurol Sci 2014;340:512.
26. Desport JC, Couratier P. Nutritional assessment in amyotrophic lateral sclerosis patients. Rev Neurol (Paris) 2006:162:4S173-6.

27. O’Reilly ÉJ, Wang H, Weisskopf MG, et al. Premorbid body mass index and risk of amyotrophic lateral sclerosis. Amyotroph Lateral Scler Frontotemporal Degener 2013;14:205-11.

28. Kaufmann P, Levy G, Thompson JL, et al. The ALSFRSr predicts survival time in an ALS clinic population. Neurology 2005; 64:38-43. 